\title{
Indian contribution to suicide research during 2005-2014: A scientometric assessment using publications and citation data
}

\section{Ritu Gupta,} Satyendra Sharma1, B. M. Gupta ${ }^{2}$

Sri Venkateswara University, Tirupati, Andhra Pradesh, 'Delhi Technology Campus, Greater Noida, Uttar Pradesh, ${ }^{2}$ National Institute of Science Technology and Development

Studies, New Delhi, India

Address for the Correspondence: Dr. B.M. Gupta,

National Institute of Science Technology and

Development Studies,

New Delhi - 110 012, India. E-mail: bmgupta1@gmail.com

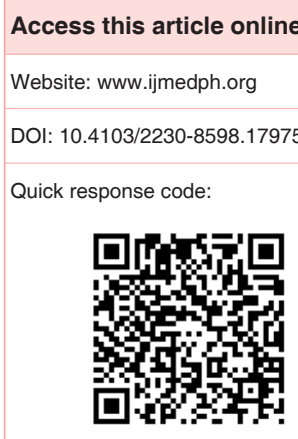

This paper analyzes 1078 India's publications on suicide research during 10 years, i.e., 2005-2014, as indexed in Scopus International Multidisciplinary Database. The study focuses on the various aspects of performance of India's suicide research, such as the publication growth, citation impact, international collaboration, subject-wise distribution of publications, contribution and citation impact of Indian organizations and authors, medium of communication, and characteristics of its high-cited papers. This study reveals that India's research output on suicides research witnessed an annual average growth rate of $10.49 \%$, registered an average citation impact per paper of 9.75 , and a share of $16.23 \%$ of international collaborative publications. India's global publication and share to world suicide research was $2.47 \%$ during 1999-2014. Medicine contributed the largest publication share of $84.32 \%$, followed by pharmacology, toxicology, and pharmaceutics and social sciences $(19.94 \%)$, environment science $(9.37 \%)$, biochemistry, genetics and molecular biology $(8.35 \%$ share), psychology $(7.05 \%$ share), neuroscience $(4.36 \%$ share), economics, econometrics, and finance $(2.23 \%$ share $)$, and immunology and microbiology $(1.95 \%$ share) during 2005-2014. About 294 organizations and 356 authors participated in 1078 Indian papers in suicide research, of which the top 15 most productive Indian organizations and authors together contributed $36.18 \%$ and $17.44 \%$ publications share and $49.58 \%$ and $56.06 \%$ citation share to the India's publications and citation output on suicide research during 2005-2014. This study also suggests the need for taking up of measures at population, sub-population, and individual levels to prevent suicide and suicide attempts. Suicide is a complex issue and therefore suicide prevention efforts require coordination and collaboration among multiple sectors of society.

Key words: Bibliometrics, India, publications, scientometrics, Suicide research

\section{INTRODUCTION}

Suicide is defined as the deliberate termination of life. The essential ingredients of a suicide are: (i) It should be an un-natural death, (ii) the desire to die should originate within him/her; and (iii) there should be some reason for ending life. ${ }^{[1]}$ Suicide is a serious public health problem; however, suicides are preventable with timely, evidence-based, and often low-cost interventions. In high-income countries, the link between suicide and mental disorders (in particular, depression and alcohol use disorders) is well established, however many suicides happen impulsively in the moments of crisis with a breakdown in the ability to deal with life stresses, such as financial problems, relationship break-up,

This is an open access article distributed under the terms of the Creative Commons AttributionNonCommercial-ShareAlike 3.0 License, which allows others to remix, tweak, and build upon the work non-commercially, as long as the author is credited and the new creations are licensed under the identical terms.

For reprints contact: reprints@medknow.com

How to cite this article: Gupta R, Sharma S, Gupta BM. Indian contribution to suicide research during 2005-2014: A scientometric assessment using publications and citation data. Int J Med Public Health 2016;6:4-12. 
or chronic pain and illness. Stigma, particularly surrounding mental disorders and suicide, means many people thinking of taking their own life or who have attempted suicide are not seeking help and are therefore not getting the help they need. In addition, other significant reasons such as experiencing conflict, disaster, violence, abuse, or loss, and a sense of isolation are strongly associated with suicidal behavior. Ingestion of pesticide, hanging, and firearms are among the most common methods of suicide globally. Around 30\% of global suicides are estimated due to pesticide self-poisoning, most of which occur in rural agricultural areas in low- and middle-income countries. Other common methods of suicide are hanging and firearms. Suicide rates are also high among vulnerable groups who experience discrimination, such as refugees and migrants; indigenous peoples; lesbian, gay, bisexual, transgender, intersex persons, and prisoners. By far, the strongest risk factor for suicide is a previous suicide attempt. ${ }^{[2,3]}$

Suicide is a global phenomenon and occurs all over the world in all regions, including high-, middle-, and low-income countries, but $75 \%$ of global suicides occurred in low- and middle-income countries in 2012. More than 800,000 people die due to suicide every year around one person every $40 \mathrm{~s}$, and for every suicide, there are many more people who attempt suicide every year. Suicides can take place at almost any age; however, suicide rates are highest in people aged 70 years and among 15-29 year-old globally. Suicides are the second leading cause of death in 15-29 year-old globally in 2012. ${ }^{[2,3]}$ In high-income countries, three times as many men die by suicide than women; however, in low- and middle-income countries, young adults and elderly women have higher rates of suicide than their counterparts in high-income countries.

In the WHO South-East Asian region, the estimated suicide rate is the highest as compared to other WHO regions. Suicide rates show a peak among the young and among the elderly. Most suicides in the world occur in the South-East Asian region $(39 \%$ of those in lowand middle-income countries in South-East Asia alone) with India accounting for the highest estimated number of suicides overall in 2012. ${ }^{[2,3]}$ The number of suicide deaths reported in India has been constantly increasing over the years in India. The number of suicide deaths in India has increased from 38,829 in 1967 to 104,713 in 1998 and to 134799 in 2014. Among the geographical states, the maximum suicides were reported in Maharashtra (16,304), Tamil Nadu (16,122), and West Bengal (14,310), constituting 12.4\%, 12.2\%, and 10.9\%, share respectively of the total suicides in India in 2014. Among 53 mega cities of India, Chennai (2214 cases), Bangalore (1906 cases), Delhi (1847 cases) together have reported almost 37\% of the total suicides in India in 2014. The suicide death rates (number of suicides per lakh of population) in cities (12.2) were higher as compared to all-India suicide rate (10.6) in 2014. The overall male:female ratio of suicides victims for 2014 was 68:32. Hanging (41.8\%), consuming poison $(26.0 \%)$, self-immolation $(6.9 \%)$, and drowning $(5.6 \%)$ were the prominent means of committing suicides in 2014. Family problems (other than marriage-related problems) (21.7\%) and illness $(18.0 \%)$ have together reported around $37 \%$ of the total suicides in
2014. Other family problems (1586), failure in examinations (1284), and illness (1105) were the main causes of suicides among children's below 18 years of age. Bankruptcy and indebtedness happen to be the major causes of suicide by farmers in India. ${ }^{[1,4]}$

\section{Literature review}

Vogelzang et al..$^{[5]}$ analyzed the publications trends in depression and suicide during 1900-2007, using scientometric methods and density-equalizing techniques. The study focused on different aspects such as growth of publications, distribution of publications by countries, authors, and journals. The published papers were also correlated with gross domestic product and purchasing power parity. Cardinal ${ }^{[6]}$ quantified certain characteristics of publications covered in a serial "Suicide and Life-Threatening Behavior" during 1971-1975, 1984-1988, and 1997-2001. The characteristics studied include geographic origin of articles, number of authors per article, number of references listed per article, and number of times an article is cited in the literature. Changes across the three periods in terms of distribution of subjects/participants by age group and gender are also examined. Goldblatt et al..$^{[7]}$ examined all publications covered in three suicide-related journals, namely Crisis: The Journal of Crisis Intervention and Suicide Prevention, Archives of Suicide Research, and Suicide and Life-Threatening Behavior during 2006-2010, and categorized each paper by subject. They found that the journals were similar with respect to subject allocation. Most papers dealt with epidemiological issues (32.7-40.1\%); prevention $(5.8-15.3 \%)$ and research $(8.3-10.6 \%)$ were the next best represented subjects. Clinical papers comprised from $2.8 \%$ to $8.2 \%$ of the studies published. English-language suicide journals publish a preponderance of epidemiological studies. Clinical studies are relatively underrepresented.

\section{OBJECTIVES}

This study makes a quantitative assessment of India's publications on suicides, as indexed in Scopus international database during 2005-2014. In particular, the study focuses on the following objectives:

- To study the growth and distribution of world literature and Indian literature on suicides

- To study the share of international collaborative publications and the contribution of major collaborative countries in India's output

- To study the distribution of citations received by Indian publications

- To study the contribution and global share of 10 most productive countries

- To study the distribution of publication output by broad subject areas, by individual rare earth elements and identification of important keywords

- To study the contribution and impact of top 15 most productive organizations and authors

- To study the medium of communication and the characteristics of top highly-cited publications. 


\section{METHODOLOGY}

The publications of top 10 most productive countries on suicides were sourced using a set of significant keywords from Scopus International Bibliographical Database (http://www.scopus. com) covering 10 years period from 2005 to 2014. The significant keyword "suicide" were used in "Title, Abstract, and Keyword" tag and restricting the hits to the period 2005-2014 in "date range tag" for searching and retrieving global publications on suicides. This statement became our main search string. The main search string was further restricted to individual 10 countries in "country tag" for obtaining publications data of these countries (as shown below). On further restricting the India's search string to "subject area tag," "country tag," "source title tag," “journal title name" and "affiliation tag," statistics on distribution of publications by subject, collaborating countries, organization, and author-wise and journal-wise, etc., were obtained. Citation data were obtained from the date of publications till October 2015.

\section{ANALYSIS}

The global and Indian publications on suicide research increased from 3493 and 74 publications in 2005 to 4559 and 152 publications in 2014, witnessing an annual average growth rate of $3.07 \%$ and $10.49 \%$ during 2005-2014. The cumulative global and India's output on suicide research increased from 18,497 and 363 publications to 43,684 and 715 publications from 2005-2009 to 2010-2014, registering a growth rate of $19.23 \%$ and $96.97 \%$. The average citations per publication (ACPP) registered by Indian publications on suicide research was 9.75 during 2005-2014, which decreased from 16.87 during 2005-2009 to 6.14 during 2010-2014 [Table 1].

Of the 1078 Indian publications on suicide research, $71.15 \%$ (767) appeared as articles, $11.69 \%(126)$ as reviews, $8.16 \%$ (88) as letters,

\begin{tabular}{|c|c|c|c|c|c|c|}
\hline \multirow{2}{*}{$\begin{array}{l}\text { Publication } \\
\text { year }\end{array}$} & \multirow{2}{*}{$\begin{array}{c}\text { World } \\
\text { TP }\end{array}$} & \multicolumn{5}{|c|}{ India } \\
\hline & & TP & TC & ACPP & ICP & $\begin{array}{c}\text { Percentage } \\
\text { ICP }\end{array}$ \\
\hline 2005 & 3493 & 74 & 1353 & 18.28 & 16 & 21.62 \\
\hline 2006 & 3677 & 60 & 830 & 13.83 & 9 & 15.00 \\
\hline 2007 & 3666 & 75 & 2551 & 34.01 & 17 & 22.67 \\
\hline 2008 & 3685 & 64 & 721 & 11.27 & 10 & 15.63 \\
\hline 2009 & 3976 & 90 & 668 & 7.42 & 19 & 21.11 \\
\hline 2010 & 3972 & 102 & 829 & 8.13 & 20 & 19.61 \\
\hline 2011 & 4253 & 151 & 905 & 5.99 & 22 & 14.57 \\
\hline 2012 & 4589 & 160 & 2345 & 14.66 & 19 & 11.88 \\
\hline 2013 & 4681 & 150 & 181 & 1.21 & 20 & 13.33 \\
\hline 2014 & 4559 & 152 & 131 & 0.86 & 23 & 15.13 \\
\hline $2005-2009$ & 18,497 & 363 & 6123 & 16.87 & 71 & 19.56 \\
\hline $2010-2014$ & 22,054 & 715 & 4391 & 6.14 & 104 & 14.55 \\
\hline $2005-2014$ & 43,684 & 1078 & 10,514 & 9.75 & 175 & 16.23 \\
\hline
\end{tabular}

$\mathrm{TP}=$ Total publications, $\mathrm{TC}=$ Total citations, $\mathrm{ACPP}=$ Average citation per paper, $\mathrm{ICP}=$ International collaborative publications
$2.51 \%$ (27) as book chapters, $2.41 \%$ (26) as conference papers, $1.95 \%(21)$ as editorials, $0.93 \%(10)$ as short surveys, $0.74 \%(8)$ as notes, $0.28 \%$ (3) articles in press, and $0.19 \%$ (2) as books during 2005-2014.

The share of international collaborative publications in India's research output on suicide was $16.23 \%$ during $2005-2014$, which decreased from $19.56 \%$ during $2005-2009$ to $14.55 \%$ during 2010-2014. Among the international collaborating countries, partners involved in suicide research in India, the largest share (40.57\%, 71 publications) came from the USA, followed by the UK (33.14\%, 58 publications), Australia (24.57\%, 43 publications), Switzerland (21 publications, 12.0\%), Canada (17 publications, 9.71\%), Japan (16 publications, 9.14\%), China (15 publications, $8.57 \%$ ), Brazil and South Africa (14 publications, 8.0\% each), and Italy (13 publications, 743\%) during 2005-2014. The international collaborative publication share in India's publication output increased by $23.24 \%$ in the USA, followed by Japan (10.64\%), Canada $(9.24 \%)$, Italy $(7.76 \%)$, and China (2.57\%), as against decrease in Switzerland (10.62\%), Australia (8.42\%), the UK (5.85\%), and South Africa (3.13\%) from 2005-2009 to 2010-2014 [Table 2]. ${ }^{[2]}$

\section{Citation distribution of papers}

Only $59.55 \%$ of the Indian publications (642) on suicide research were cited 1 or more times during 2005-2014. Of the cited publications, $1.30 \%$ share (14 publications) of India's publications on suicide (received 100 or more citations) registered $48.39 \%$ India's citation share (5088 citations), 1.76\% share (19 publications) of India's publications (received 51-100 citations) registered $12.52 \%$ India's citation share (1316 citations), 1.86\% share (20 publications) of India's publications (received 31-50 citations) registered 7.07\% India's citation share (743 citations), 8.72\% share (1597 publications) of India's publications (received 11-30 citations) registered $15.19 \%$ India's citation share (1597 citations), and 45.92\% share (495 publications) of India's publications (received 1-10 citations) registered $16.83 \%$ India's citations share (1770 citations) during 2005-2014 [Table 3].

\section{Global publication output and share of top 10 most productive countries}

The top 10 most productive countries in terms of publication output on suicide research contributed individually 1053-14,021 publications and together contributed 43,684 publications, accounting for $71.82 \%$ share of the global publications output on suicide research during 2005-2014. The global publication share of the top 10 most productive countries on suicide research varied from $2.41 \%$ to $32.10 \%$, with largest share $(32.10 \%$ ) coming from the USA, followed by the UK $(9.60 \%)$, Germany (5.16\%), Canada (4.96\%), Australia (4.81\%), France (4.18\%), Italy (3.26\%), Japan (2.87\%), India (2.47\%), and China (2.41\%) during 2005-2014. The global publication share of the top 10 most productive countries increased by $4.93 \%$ in the USA, followed by Australia (2.11\%), India $(1.28 \%)$, Canada $(1.23 \%)$, the UK (1.11\%), Italy $(0.77 \%)$, France and 


\begin{tabular}{l} 
Table 2: Share of significant foreign partner countries in India's international collaborative output during \\
$\begin{array}{l}\text { 2005-2014 } \\
\text { Collaborative countries }\end{array}$ \\
\cline { 2 - 6 }
\end{tabular}

\begin{tabular}{lcccc}
\multicolumn{5}{l}{$\begin{array}{l}\text { Table 3: Distribution of citations by papers on } \\
\text { India's suicide research during 2005-2014 }\end{array}$} \\
$\begin{array}{l}\text { Indange of } \\
\begin{array}{l}\text { Rangers } \\
\text { citations }\end{array}\end{array}$ & Papertions & $\begin{array}{c}\text { Percentage } \\
\text { papers }\end{array}$ & $\begin{array}{c}\text { Percentage } \\
\text { citations }\end{array}$ \\
\hline 0 & 436 & 0 & 40.45 & 0.00 \\
$1-10$ & 495 & 1770 & 45.92 & 16.83 \\
$11-30$ & 94 & 1597 & 8.72 & 15.19 \\
$31-50$ & 20 & 743 & 1.86 & 7.07 \\
$51-100$ & 19 & 1316 & 1.76 & 12.52 \\
$>100$ & 14 & 5088 & 1.30 & 48.39 \\
Total & 1078 & 10,514 & 100.00 & 100.00 \\
\hline
\end{tabular}

China (0.69\% each), and Germany $(0.31 \%)$, as against decrease by $0.11 \%$ in Japan from 2005-2009 to 2010-2014 [Table 4].

\section{Subject-wise distribution of Indian publications}

India's publication output on suicide research during 2005-2014 has been published in the context of nine subject fields (as reflected in Scopus database classification), with highest number of publications coming from medicine (with $84.32 \%$ share), followed by pharmacology, toxicology, and pharmaceutics and social sciences (19.94\% share each), environment science $(9.37 \%$ share), biochemistry, genetics and molecular biology (8.35\% share), psychology ( $7.05 \%$ share), neuroscience ( $4.36 \%$ share), economics, econometrics and finance (2.23\% share), and immunology and microbiology (1.95\% share) during 2005-14. On analyzing the trends using activity index, it was found that research activity has increased in medicine (from 95.07 to 102.50), pharmacology, toxicology and pharmaceutics (from 74.59 to 112.90), social sciences (from 85.64 to 107.29), environment science (from 49.98 to 125.39), psychology (from 50.80 to 124.98), economics, and econometrics and finance (from 61.87 to 119.36), as against decrease in biochemistry, genetics and molecular biology (from 112.19 to 93.81), neurosciences (from 126,37 to 86.61), and immunology and microbiology (from 183.84 to 57.44 ) from 2005-2009 to 2010-2014. Neurosciences and immunology and microbiology registered the highest citation impact per paper 15.98 and 14.29, followed by medicine (10.82), psychology (8.87), biochemistry, genetics and molecular biology
(8.0), economics, econometrics and finance (4.54), social sciences (3.80), and environment science (2.77) during 2005-2014 [Table 5].

\section{Significant keywords}

About 40 significant keywords have been identified in the Indian suicide research output, which throw light on the nature of research as the causes and factors leading to suicides in India. The largest number of papers (631) was found on keyword suicide, followed by intoxication (209), psychosis autopsy (183), depression anxiety (159), poisoning (136), hanging (110), etc., [Table 6].

\section{Contribution and citation impact of top 15 most productive organizations}

In all 294 organizations participated in 1078 Indian papers in suicide research, of which 240 organizations contributed 1-5 papers, 35 organizations: 6-10 papers, 13 organizations: $11-20$ papers, and the rest 38-56 papers during 2005-2014. The top 15 most productive Indian organizations involved in Indian suicide research individually published 11-56 papers and together contributed $36.18 \%$ publications share (390 papers) and $49.58 \%$ citation share (5213 citations) to the India's publications and citation output on suicide research during 2005-2014. The scientometric profile of 15 most productive Indian organizations involved in suicide research is presented in Table 7. Six organizations have registered higher publication productivity per organization than the group average (26): NIMANS-Bangalore (56 publications), AIIMS-New Delhi (55 publications), CMC-Vellore and KMC-Mangalore (42 publications each), KMC-Manipal (40 publications), and PGIMER-Chandigarh (38 publications) during 2005-2014. The average citation per paper registered by top 15 most productive Indian organizations was 13.37 and only two organizations have scored more than average ACPP PG all 15 organizations: AIIMS-New Delhi (56.29) and CMC-Vellore (15.93) during 2005-2014. The average h-index registered by top 15 most productive Indian organizations was 5.73 and only 7 organizations have scored more than average h-index of all 15 organizations: AIIMS-New Delhi (13), CMC, Vellore (13), NIHMANS-Bangalore 


\begin{tabular}{|c|c|c|c|c|c|c|}
\hline \multirow[t]{2}{*}{ Name of the country } & \multicolumn{3}{|c|}{ Number of publications } & \multicolumn{3}{|c|}{ Global share of publications } \\
\hline & 2005-2009 & 2010-2014 & $2005-2014$ & 2005-2009 & 2010-2014 & 2005-2014 \\
\hline USA & 5900 & 8121 & 14,021 & 31.90 & 36.82 & 32.10 \\
\hline UK & 1801 & 2392 & 4193 & 9.74 & 10.85 & 9.60 \\
\hline Germany & 998 & 1258 & 2256 & 5.40 & 5.70 & 5.16 \\
\hline Canada & 865 & 1303 & 2168 & 4.68 & 5.91 & 4.96 \\
\hline Australia & 746 & 1354 & 2100 & 4.03 & 6.14 & 4.81 \\
\hline France & 763 & 1061 & 1824 & 4.12 & 4.81 & 4.18 \\
\hline Italy & 573 & 853 & 1426 & 3.10 & 3.87 & 3.26 \\
\hline Japan & 583 & 671 & 1254 & 3.15 & 3.04 & 2.87 \\
\hline India & 363 & 715 & 1078 & 1.96 & 3.24 & 2.47 \\
\hline China & 411 & 642 & 1053 & 2.22 & 2.91 & 2.41 \\
\hline World & 18,497 & 22,054 & 43,684 & 100.00 & 100.00 & 100.00 \\
\hline
\end{tabular}

\begin{tabular}{|c|c|c|c|c|c|c|c|c|c|}
\hline \multirow[t]{2}{*}{ Subject } & \multicolumn{3}{|c|}{ Total papers } & \multicolumn{2}{|c|}{ Activity index } & \multirow{2}{*}{$\begin{array}{c}\text { TC } \\
2005-14\end{array}$} & \multirow{2}{*}{$\begin{array}{c}\text { ACPP } \\
2005-2014\end{array}$} & \multirow{2}{*}{$\begin{array}{c}\text { HI } \\
\text { 2005-2014 }\end{array}$} & \multirow{2}{*}{$\begin{array}{c}\text { Percentage TP } \\
2005-2014\end{array}$} \\
\hline & 2005-2009 & 2010-2014 & $2005-2014$ & 2005-2009 & $2010-2014$ & & & & \\
\hline Medicine & 291 & 618 & 909 & 95.07 & 102.50 & 9839 & 10.82 & 38 & 84.32 \\
\hline $\begin{array}{l}\text { Pharmacology, toxicology, } \\
\text { and pharmaceutics }\end{array}$ & 54 & 161 & 215 & 74.59 & 112.90 & 510 & 2.37 & 12 & 19.94 \\
\hline Social sciences & 62 & 153 & 215 & 85.64 & 107.29 & 816 & 3.80 & 15 & 19.94 \\
\hline Environment science & 17 & 84 & 101 & 49.98 & 125.39 & 280 & 2.77 & 10 & 9.37 \\
\hline $\begin{array}{l}\text { Biochemistry, genetics, } \\
\text { and molecular biology }\end{array}$ & 34 & 56 & 90 & 112.19 & 93.81 & 720 & 8.00 & 15 & 8.35 \\
\hline Psychology & 13 & 63 & 76 & 50.80 & 124.98 & 674 & 8.87 & 13 & 7.05 \\
\hline Neurosciences & 20 & 27 & 47 & 126.37 & 86.61 & 751 & 15.98 & 14 & 4.36 \\
\hline $\begin{array}{l}\text { Economics, econometrics } \\
\text { and Finance }\end{array}$ & 5 & 19 & 24 & 61.87 & 119.36 & 109 & 4.54 & 5 & 2.23 \\
\hline $\begin{array}{l}\text { Immunology and } \\
\text { microbiology }\end{array}$ & 13 & 8 & 21 & 183.84 & 57.44 & 300 & 14.29 & 10 & 1.95 \\
\hline Total of India & 363 & 715 & 1078 & 100.00 & 100.00 & & & & \\
\hline
\end{tabular}

$\mathrm{TP}=$ Total publications, $\mathrm{TC}=$ Total citations, $\mathrm{ACPP}=$ Average citation per paper, $\mathrm{HI}=\mathrm{H}$-index

(9), KMC-Mangalore (9), PGIMER-Chandigarh (8), KMC-Manipal (8), and IIT-Guwahati (6) during 2005-2014. The average share of international collaborative publications (ICP) of top 15 most productive organizations was $17.18 \%$, and six organizations have achieved more than the average ICP share of all 15 countries: AIIMS-New Delhi (30.91\%), Mysore Medical College (27.78\%), LHMC-New Delhi (25.0\%), NIMANS-Bangalore (23.21\%), CMC-Vellore (19.05\%), KMC-Manipal (17.50\%), and KMC-Manipal (16.67\%) during 2005-2014.

\section{Contribution and citation impact of top 15 most productive authors}

In the 1078 publications on Indian suicide research, 356 authors participated, of which 316 authors published $1-5$ papers, 33 authors: 6-10 papers, 4 authors: 11-20 papers, and 1 author: 23 papers during 2005-2014. The top 15 most productive Indian authors have individually published 8-24 papers and together contributed $17.44 \%$ publication share (188 papers) and 56.06\% citation share (5894 citations) to the India's publications and citation output on suicide research during 2005-2014. The scientometric profile of the most productive 15 Indian authors is presented in Table 8.
Five authors have registered higher publication productivity per author than the group average (12.53): T. Kanchan (24 papers), R.G. Menezes (23 papers), V. Patel and M. Arun (18 papers each), and L. Vijaya Kumar (17 papers) during 2005-2014. Seven Indian authors have registered h-index more than the group average (31.35) during 2005-2014: L. Vijaya Kumar (151.35) and V. Patel (122.72) during 2005-2014. Five Indian authors have achieved higher h-index value than the group's average (5.87) during 2005-2014: V. Patel (18), L. Vijaya Kumar (13) T. Kanchan (8), J.V. Peter and R.G. Menezes (7 each) during 2005-2014.

Five Indian authors have registered higher international collaborative publications (ICP) share than the group average (27.66) during 2005-2014: V. Patel (94.44\%), L. Vijaya Kumar (70.59\%), J.V. Peter, M.K. Mohanty and M. Arun (33.33\% each) during 2005-2014.

\section{Medium of communication}

Of 1078 publications from India on suicide research, 97.03\% (1046) publications appeared in journals, 2.69\% (29) as books, $1.19 \%$ (2) in book series, and $0.09 \%$ (1) as conference papers during 2005-2014. The 1046 journal publications were published in 158 journals, of 


\begin{tabular}{|c|c|}
\hline Name of keyword & Number of papers \\
\hline Suicide & 631 \\
\hline Intoxication & 209 \\
\hline Psychosis autopsy & 183 \\
\hline Depression anxiety & 159 \\
\hline Poisoning & 136 \\
\hline Suicide attempt & 112 \\
\hline Hanging & 110 \\
\hline Homicide & 110 \\
\hline Mental disease & 102 \\
\hline Sex difference & 83 \\
\hline Death & 72 \\
\hline Suicide ideation & 65 \\
\hline Disease severity & 63 \\
\hline Marriage & 63 \\
\hline Suicide behavior & 57 \\
\hline Asphyxia & 56 \\
\hline Mental health & 56 \\
\hline Mental discord & 53 \\
\hline Stomach lavage & 47 \\
\hline Organo-phosphorous compounds & 46 \\
\hline Auto-mutilation & 45 \\
\hline Schizophrenia & 45 \\
\hline Pesticide & 44 \\
\hline Medio-legal aspects & 42 \\
\hline Drowning & 42 \\
\hline Alcoholism & 41 \\
\hline Psychosis & 33 \\
\hline Anxiety & 32 \\
\hline Violence & 31 \\
\hline Self-poisoning & 36 \\
\hline Neck injuries & 26 \\
\hline Insecticides & 26 \\
\hline Thorax radiography & 26 \\
\hline Bipolar disorder & 24 \\
\hline Kerosene & 26 \\
\hline Mental stress & 23 \\
\hline Mood disorder & 23 \\
\hline Self-injurious behavior & 22 \\
\hline
\end{tabular}

which 142 journals published $1-10$ papers, 10 journals $11-20$ papers, 2 journals $21-30$ papers, and the rest of the journals 38-84 papers during 2005-2014. The top 15 most productive journals individually published 14-84 papers and together contributed 460 papers, which account for $42.67 \%$ share of its total journals output. The cumulated publication output in 15 journals increased from 33.33\% during 2005-2009 to $47.41 \%$ during 2010-2014. The largest number of publications (84) was published in Medico Legal Update, followed by Indian Journal of Forensic Medicine and Toxicology (72 papers), Indian Journal of Psychiatry (41 papers), Journal of Forensic and Legal Medicine (40 papers), etc. [Table 9].

\section{High-cited papers}

There were 14 high-cited papers, which have received citations from 102 to 1844 , with 9 papers in citation range from 102 to 192 , 3 papers from 254 to 469 citation range, and 2 papers from 929 to 1844 citation range during 2005-2014. These 14 papers together received 5105 citations, with an average citation per paper of 364.64. All 14 high-cited papers (4 reviews and 10 articles) were involved in international collaboration and have the participation of 26 Indian authors and 17 Indian organizations participated. The most prominent participatory Indian authors were: V. Patel (4 papers), R. Sagar (3 papers), L. Vijaykumar (2 papers), and all other others published 1 paper each. Among organizations, the largest number of papers (5) came from All India Institute of Medical Sciences, New Delhi, followed by Sanganath Center, Goa (4 papers), Voluntary Health Services, Sneha, Chennai (3 papers), and all other organizations published 1 paper each: Betty Crown Research and Innovation Center, Ludhiana, Byrraju Foundation, Hyderabad, Care Foundation, Hyderabad, Centre for Disease Control and Prevention, New Delhi, Christian Medical College, Vellore, Sanjay Gandhi Postgraduate Institute of Medical Sciences, Lucknow, Schizophrenia Foundation, Chennai, Psychiatry Clinic, Vasant Vihar, New Delhi, and Voluntary Health Association of Goa. These 14 high-cited papers were published in 8 journals, with 6 papers in The Lancet and 1 paper each in the Archives of General Psychiatry, British Journal of Psychiatry, Bulletin of the WHO, International Journal of Epidemiology, Journal of Clinical Psychiatry, Psychology Medicine, and Schizophrenia Bulletin. A list of the top 14 high-cited papers is enclosed in Appendix 1.

\section{SUMMARY AND SUGGESTIONS}

The world and India published 43,684 and 1078 publications in suicide research, and they grew at an annual average growth rate of $3.07 \%$ and $10.49 \%$ during 2005-2014. The citation impact per paper registered by India's publications on suicide research was 9.75 during 2005-2014, decreasing from 16.87 during 2005-2009 to 6.14 during 2010-2014. Of the total publications on suicide research, only $59.55 \%$ publications were cited 1 or more times during 2005-2014. India's research output on suicides had $16.23 \%$ share of international collaborative papers, witnessing decrease from $19.56 \%$ to $14.55 \%$ from 2005-2009 to 2010-2014. The United States was the largest collaborative partner in India's suicide research with a publication share of $40.57 \%$, followed by the UK (33.14\%), Australia $(24.57 \%$, 43 publications), Switzerland (21 publications, 12.0\%), Canada (17 publications, 9.71\%), Japan (16 publications, 9.14\%), China (15 publications, 8.57\%), etc., during 2005-2014. Among subjects distribution of papers, medicine contributed the largest publication share of $84.32 \%$, followed by pharmacology, toxicology, and pharmaceutics and social sciences (19.94\%), environment science (9.37\%), biochemistry, genetics and molecular biology $(8.35 \%$ share), psychology (7.05\% share), neuroscience (4.36\% share), economics, econometrics and finance $(2.23 \%$ share), and immunology and microbiology (1.95\% share) during 2005-2014. Exactly, 294 organizations and 356 authors participated in 1078 Indian papers in suicide research. The top 15 most productive Indian organizations and authors together contributed $36.18 \%$ and $17.44 \%$ publications 


\begin{tabular}{|c|c|c|c|c|c|c|}
\hline Name of the organization & TP & TC & ACPP & HI & ICP & Percentage ICP \\
\hline National Institute of Mental Health and Neuro Sciences, Bangalore & 56 & 338 & 6.04 & 9 & 13 & 23.21 \\
\hline All India Institute of Medical Sciences, New Delhi & 55 & 3096 & 56.29 & 13 & 17 & 30.91 \\
\hline Christian Medical College, Vellore & 42 & 669 & 15.93 & 12 & 8 & 19.05 \\
\hline Kasturba Medical College, Mangalore & 42 & 238 & 5.67 & 9 & 7 & 16.67 \\
\hline Kasturba Medical College, Manipal & 40 & 179 & 4.48 & 8 & 7 & 17.50 \\
\hline Postgraduate Institute of Medical Education and Research, Chandigarh & 38 & 283 & 7.45 & 8 & 5 & 13.16 \\
\hline Mysore Medical College & 18 & 63 & 3.50 & 5 & 5 & 27.78 \\
\hline $\begin{array}{l}\text { Jawaharlal Institute of Postgraduate Medical Education and Research, } \\
\text { Pondicherry }\end{array}$ & 14 & 94 & 6.71 & 4 & 2 & 14.29 \\
\hline CSM Medical University, Lucknow & 13 & 11 & 0.85 & 2 & 0 & 0.00 \\
\hline Regional Institute of Medical Science, Manipur & 13 & 7 & 0.54 & 1 & 0 & 0.00 \\
\hline Armed Forces Medical College, Pune & 12 & 11 & 0.92 & 2 & 0 & 0.00 \\
\hline Government Medical College, Nagpur & 12 & 9 & 0.75 & 1 & 0 & 0.00 \\
\hline Lady Harding Medical College, Delhi & 12 & 38 & 3.17 & 3 & 3 & 25.00 \\
\hline JJM Medical College, Davangere & 12 & 35 & 2.92 & 3 & 0 & 0.00 \\
\hline Indian Institute of Technology, Guwahati & 11 & 142 & 12.91 & 6 & 0 & 0.00 \\
\hline Total of 15 organizations & 390 & 5213 & 13.37 & 5.73 & 67 & 17.18 \\
\hline Total of India & 1078 & 10514 & & & & \\
\hline Share of 15 organizations in India's total output & 36.18 & 49.58 & & & & \\
\hline
\end{tabular}

$\mathrm{TP}=$ Total publications, $\mathrm{TC}=$ Total citations, $\mathrm{ACPP}=$ Average citation per paper, $\mathrm{ICP}=$ International collaborative publications, $\mathrm{HI}=\mathrm{H}$-index

\begin{tabular}{|c|c|c|c|c|c|c|c|}
\hline Name & Affiliation & TP & TC & ACPP & $\mathrm{HI}$ & ICP & Percentage ICP \\
\hline T. Kanchan & KMC-Mangalore & 24 & 178 & 7.42 & 8 & 3 & 12.50 \\
\hline R.G. Menezes & KMC-Mangalore & 23 & 156 & 6.78 & 7 & 6 & 26.09 \\
\hline V. Patel & Sanganat Center, Goa & 18 & 2209 & 122.72 & 18 & 17 & 94.44 \\
\hline M. Arun & KMC-Manipal & 18 & 58 & 3.22 & 4 & 6 & 33.33 \\
\hline L. Vijaya Kumar & SNEHA and Voluntary Health Services, Chennai & 17 & 2573 & 151.35 & 13 & 12 & 70.59 \\
\hline S.S. Ghosh & IIT-Guwahati & 11 & 141 & 12.82 & 6 & 0 & 0.00 \\
\hline K.S. Jacob & CMC-Vellore & 10 & 188 & 18.80 & 6 & 0 & 0.00 \\
\hline J.V. Peter & CMC-Vellore & 9 & 110 & 12.22 & 7 & 3 & 33.33 \\
\hline M.K. Mohanty & PSIMS & 9 & 135 & 15.00 & 5 & 3 & 33.33 \\
\hline V.N. Ambade & Vasantrao Naik Medical College, Yeotmal, Maharashtra & 9 & 66 & 7.33 & 3 & 0 & 0.00 \\
\hline C. Behera & AFMC-Pune & 8 & 6 & 0.75 & 1 & 0 & 0.00 \\
\hline S.K. Praharaj & Central Institute of Psychiatry, Ranchi & 8 & 18 & 2.25 & 3 & 0 & 0.00 \\
\hline S. Grover & PGIMER-Chandigarh & 8 & 2 & 0.25 & 1 & 0 & 0.00 \\
\hline V. Palimar & KMC-Manipal & 8 & 40 & 5.00 & 4 & 1 & 12.50 \\
\hline \multirow[t]{4}{*}{ P. Rastogi } & KMC-Mangalore & 8 & 14 & 1.75 & 2 & 1 & 12.50 \\
\hline & Total of 15 authors & 188 & 5894 & 31.35 & 5.87 & 52 & 27.66 \\
\hline & Total of India & 1078 & 10,514 & & & & \\
\hline & Share of 15 authors in India's total output & 17.44 & 56.06 & & & & \\
\hline
\end{tabular}

$\mathrm{TP}=$ Total publications, $\mathrm{TC}=$ Total citations, $\mathrm{ACPP}=$ Average citation per paper, $\mathrm{ICP}=$ International collaborative publications, $\mathrm{HI}=\mathrm{H}$-index

share and $49.58 \%$ and $56.06 \%$ citation share to the India's publications and citation output on suicide research during 2005-2014. Of 1078 India's publications on suicide research, $97.03 \%$ appeared in 158 journals during 2005-2014. The top 15 most productive journals account for $42.67 \%$ share of its total journals output.

The prevention of suicide has not been adequately addressed in India due to a lack of awareness of suicide as a major public health problem and the taboo of societies to openly discuss it. To date, only a few countries have included suicide prevention among their health priorities and only 28 countries report having national suicide prevention strategy. Raising community awareness and breaking down the taboo is important for countries to make progress in preventing suicide. Knowledge of the most commonly used suicide methods is important to devise prevention strategies in India which have shown to be effective, such as restriction of access to means of suicide. Suicides are preventable. There are a number of measures that can be taken at population, sub-population, and individual levels to prevent suicide and suicide attempts. These includes educating access to the means of suicide (e.g., pesticides, firearms, and certain medications), reporting by media in a responsible way, introducing alcohol policies to reduce the harmful use of alcohol, 


\begin{tabular}{|c|c|c|c|}
\hline \multirow[t]{2}{*}{ Name of the journal } & \multicolumn{3}{|c|}{ Number of papers } \\
\hline & 2005-2009 & 2010-2014 & 2005-2014 \\
\hline Medico Legal Update & 22 & 62 & 84 \\
\hline $\begin{array}{l}\text { Indian Journal of Forensic } \\
\text { Medicine and Toxicology }\end{array}$ & 7 & 65 & 72 \\
\hline Indian Journal of Psychiatry & 5 & 36 & 41 \\
\hline $\begin{array}{l}\text { Journal of Forensic and Legal } \\
\text { Medicine }\end{array}$ & 18 & 22 & 40 \\
\hline $\begin{array}{l}\text { Journal of the Indian Academy } \\
\text { of Forensic Medicine }\end{array}$ & 0 & 38 & 38 \\
\hline $\begin{array}{l}\text { Journal of the Forensic } \\
\text { Medicine and Toxicology }\end{array}$ & 13 & 13 & 26 \\
\hline Medical Sciences and the Law & 14 & 11 & 25 \\
\hline British Journal of Psychiatry & 9 & 11 & 20 \\
\hline The Lancet & 10 & 8 & 18 \\
\hline $\begin{array}{l}\text { International Journal of Medical } \\
\text { Toxicology and Legal Practice }\end{array}$ & 11 & 7 & 18 \\
\hline $\begin{array}{l}\text { Indian Journal of } \\
\text { Psychological Medicine }\end{array}$ & 0 & 18 & 18 \\
\hline $\begin{array}{l}\text { Indian Journal of Critical Care } \\
\text { Medicine }\end{array}$ & 6 & 10 & 16 \\
\hline Asian Journal of Psychiatry & 0 & 16 & 16 \\
\hline $\begin{array}{l}\text { Journal of Punjab Academy } \\
\text { of Forensic Medicine and } \\
\text { Toxicology }\end{array}$ & 0 & 14 & 14 \\
\hline $\begin{array}{l}\text { Indian Journal of Medical } \\
\text { Research }\end{array}$ & 6 & 8 & 14 \\
\hline Total of 15 journals & 121 & 339 & 460 \\
\hline Total of India & 363 & 715 & 1078 \\
\hline $\begin{array}{l}\text { Share of } 15 \text { journals in India's } \\
\text { total output }\end{array}$ & 33.33 & 47.41 & 42.67 \\
\hline
\end{tabular}

early identification, treatment, and care of people with mental and substance use disorders, chronic pain and acute emotional distress,

\section{APPENDIX 1}

\section{List of top 14 highly cited papers during 2005-2014}

1. Lozano R, Naghavi M, Foreman K, Lim S, Shibuya K, Aboyans V, et al. Global and regional mortality from 235 causes of death for 20 age groups in 1990 and 2010: A systematic analysis for the Global Burden of Disease Study 2010. Lancet 2012;380 (9859):2095-128. Cited 1844 times.

Institute for Health Metrics and Evaluation, University of Washington, Seattle, USA; Sanjay Gandhi Postgraduate Institute of Medical Sciences, Lucknow, India; All India Institute of Medical Sciences, New Delhi, India; Betty Cowan Research and Innovation Center, Ludhiana, India and Voluntary Health Services, Sneha, Chennai, India et al.

2. Prince M, Patel V, Saxena S, Maj M, Maselko J, Phillips MR, et al. No health without mental health. Lancet 2007;370 (9590):859-77. Cited 929 times.

King's College London, Centre for Public Mental Health, Health Service and Population Research Department, Institute training of nonspecialized health workers in the assessment and management of suicidal behavior, and follow-up care for people who attempted suicide and provision of community support. Suicide is a complex issue and therefore suicide prevention efforts require coordination and collaboration among multiple sectors of society, including the health sector and other sectors such as education, labor, agriculture, business, justice, law, defense, politics, and the media. These efforts must be comprehensive and integrated as no single approach alone can make an impact on an issue as complex as suicide.

\section{Financial support and sponsorship}

Nil.

\section{Conflicts of interest}

There are no conflicts of interest.

\section{REFERENCES}

1. National Crime Records Bureau. Accidents deaths and suicides in India. New Delhi; National Crime Bureau Records Ministry of Home Affairs July 2015.

2. World Health Organization (WHO). Suicide. Key Facts. Fact Sheet No. 398; August, 2015. Available from: http://www.who.int/mediacentre/ factsheets/fs398/en/. [Last accessed on 2015 Nov 01].

3. First WHO Report on Suicide Prevention; 4 September, 2014. Available from: http://www.who.int/mediacentre/news/releases/2014/ suicide-prevention-report/en/News release. [Last accessed on 2015 Nov 01].

4. Suicide in India; 30 November, 2015. Available from: https://www. en.wikipedia.org/wiki/Suicide_in_India. [Last accessed on 2015 Nov 01].

5. Vogelzang BH, Scutaru C, Mache S, Vitzthum K, Quarcoo D, Groneberg DA. Depression and suicide publication analysis, using density equalizing mapping and output benchmarking. Indian J Psychol Med 2011;33:59-65.

6. Cardinal $\mathrm{C}$. Three decades of suicide and life-threatening behavior: $\mathrm{A}$ bibliometric study. Suicide Life Threat Behav 2008;38:260-73.

7. Goldblatt MJ, Schechter M, Maltsberger JT, Ronningstam E. Comparison of journals of suicidology: A bibliometric study from 2006-2010. Crisis 2012;33:301-5.

of Psychiatry, London, U.K; London School of Hygiene and Tropical Medicine, Department of Epidemiology and Population Health, U.K.; Sangath, Goa, India et al.

3. Patel V, Flisher AJ, Hetrick S, McGorry P. Mental health of young people: A global public-health challenge. Lancet 2007;369 (9569):1302-13. Cited 469 times.

London School of Hygiene and Tropical Medicine, Department of Epidemiology and Public Health London, United Kingdom; Sangath Centre, 841/1 Alto Porvorim, Goa 403521, India et al.

4. Merikangas KR, Jin R, He JP, Kessler RC, Lee S, Sampson NA, et al. Prevalence and correlates of bipolar spectrum disorder in the world mental health survey initiative. Arch Gen Psychiatry 2011;68 (3):241-51. Cited 349 times.

National Institute of Mental Health, Genetic Epidemiology Research Branch, Bldg. 35, 35 Convent Dr, Bethesda, MD 20892, United States; Department of Psychiatry, All India Institute of Medical Sciences, Delhi, India et al.

5. Lancet Global Mental Health Group, Chisholm D, Flisher AJ, Lund C, Patel V, Saxena S, et al. Scale up services for mental 
disorders: A call for action. Lancet 2007;370 (9594):1241-52. Cited 254 times.

Department of Health Systems Financing, World Health Organization, Geneva, Switzerland; Department of Epidemiology and Population Health, Sangath, Goa, India et al.

6. Nock MK, Hwang I, Sampson N, Kessler RC, Angermeyer M, Beautrais A, et al. Cross-national analysis of the associations among mental disorders and suicidal behavior: Findings from the WHO World Mental Health Surveys. PLoS Med 2009;6 (8):e1000123. Cited 192 times.

Harvard University, Department of Psychology, Cambridge, MA, United States, Department of Psychiatry, All India Institute of Medical Sciences, New Delhi, India et al.

7. Jacob KS, Sharan P, Mirza I, Garrido-Cumbrera M, Seedat S, Mari JJ, et al. Mental health systems in countries: Where are we now? Lancet 2007;370 (9592):1061-77. Cited 171 times.

Christian Medical College, Department of Psychiatry, Vellore, India; All India Institute of Medical Sciences, Department of Psychiatry, New Delhi, India; All India Institute of Medical Sciences, Department of Biostatistics New Delhi, India et al.

8. Bertolote JM, Fleischmann A, De Leo D, Bolhari J, Botega N, De Silva D, et al. Suicide attempts, plans, and ideation in culturally diverse sites: The WHO SUPRE-MISS community survey. Psychol Med 2005;35 (10):1457-65. Cited 152 times. Department of Mental Health and Substance Abuse, World Health Organization, CH-1211 Geneva 27, Switzerland; Department of Psychiatry, Voluntary Health Services, SNEHA, Kotturpuram, Chennai, India et al.

9. Khanna S, Vieta E, Lyons B, Grossman F, Eerdekens M, Kramer M. Risperidone in the treatment of acute mania: Double-blind, placebo-controlled study. Br J Psychiatry 2005;187:229-34. Cited 147 times.

Psychiatric Clinic, Vasant Vihar, New Delhi, India et al.

10. Patel V, Weiss HA, Chowdhary N, Naik S, Pednekar S, Chatterjee $\mathrm{S}$, et al. Effectiveness of an intervention led by lay health counsellors for depressive and anxiety disorders in primary care in Goa, India (MANAS): A cluster randomised controlled trial. Lancet 2010;376 (9758):2086-95. Cited 139 times.
Medical Research Council Tropical Epidemiology Group, London, United Kingdom; Sangath Centre, Alto Porvorim, Goa, India; Voluntary Health Association of Goa, Goa, India et al.

11. Joshi R, Cardona M, Iyengar S, Sukumar A, Raju CR, Raju KR, et al. Chronic diseases now a leading cause of death in rural India - Mortality data from the Andhra Pradesh Rural Health Initiative. Int J Epidemiol 2006;35 (6):1522-9. Cited 138 times. The George Institute for International Health, Missenden Road, Sydney, NSW 2050, Australia; Byrraju Foundation, Satyam Enclave, 2-74 Jeedimetla Village, Hyderabad, Andhra Pradesh 500855, India; CARE Foundation, Banjara Hills, Hyderabad, Andhra Pradesh, India; Centre for Chronic Disease Control, V15 Green Park Extension, New Delhi 110016, India et al.

12. Fleischmann A, Bertolote JM, Wasserman D, De Leo D, Bolhari J, Botega NJ, et al. Effectiveness of brief intervention and contact for suicide attempters: A randomized controlled trial in five countries. Bull World Health Organ 2008;86 (9):703-9. Cited 115 times.

Department of Mental Health and Substance Abuse, World Health Organization, CH-1211 Geneva 27, Switzerland; Department of Psychiatry, Kotturpuram, Chennai, India et al.

13. Cohen A, Patel V, Thara R, Gureje O. Questioning an axiom: Better prognosis for schizophrenia in the developing world? Schizophr Bull 2008;34 (2):229-44. Cited 104 times.

Department of Social Medicine, Harvard Medical School, 641 Huntington Avenue, Boston, MA 02115, United States; Schizophrenia Research Foundation, Chennai, India et al.

14. Borges G, Nock MK, Haro Abad JM, Hwang I, Sampson NA, Alonso J, et al. Twelve-month prevalence of and risk factors for suicide attempts in the World Health Organization World Mental Health Surveys. J Clin Psychiatry 2010;71 (12):1617-28. Cited 102 times.

Department of Health Care Policy, Harvard Medical School, 180 Longwood Ave, Boston, MA 02115, United States; All India Institute of Medical Sciences, New Delhi, India et al. 